\title{
Quartzite and Vein Quartz as Lithic Raw Materials Reconsidered: A View from the Korean Paleolithic
}

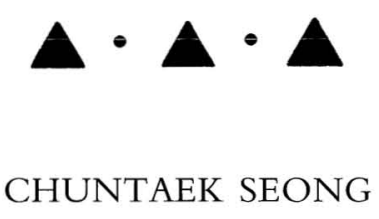

Since THe EXCAVAtion OF SokCHANG-RI (Sohn 1968, 1970, 1993) in southern Korea by local scholars in the $1960 \mathrm{~s},{ }^{1}$ the last few decades witnessed a significant increase in the number of discovered and excavated Paleolithic sites. From the late 1970s, Chongokni (Jeongok-ri), known for its "Acheulian-like" handaxes, and neighboring sites along the Imjin-Hantan River have been excavated extensively (NICP 1999; Yi and Clark 1983; Fig. 1, also see Fig. 3). A series of salvage archaeological expeditions and both occasional and systematic site surveys have revealed a dense distribution of Paleolithic locations in regions such as the Imjin-Hantan River and Boseong River valleys. The number of archaeological locations including surface scatters yielding Paleolithic chipped stone artifacts well exceeds 500 in the southern Korean Peninsula (Choi B. et al. 2001; Lee G. 1999, 2001; KPM 2001; Yi 2001).

The majority of Korean Paleolithic materials are quartzite and vein quartz artifacts. The raw materials often account for 90 percent of the total artifact collection in earlier assemblages, while the usage of the materials decreases in later industries. As J. D. Clark (1983:595) pointed out, it is believed that "informality is the keynote" of the industry as represented by the collection from Chongokni. Because of this notion, the trend of uncritically accepting many European Paleolithic artifact types has been questioned, because European typology is too specific to apply to Korean Paleolithic artifacts (Bae 1988; NICP 1999; Yi 1989). ${ }^{2}$ Given this supposed informality, it is not desirable to examine the industry based on an established classification focusing on general morphology. Some limitations, however, can also be raised: the evolution of lithic technology in the Late Paleolithic is poorly understood due to the widely held notion of an unchanging informal technology relying on coarse materials. It is generally believed that this crude technology lasted until the last part of the Pleistocene without significant change (Bae 1997:227, 1999; Chung 1997; Lee H. 2000; Park 2001; Yi 1999). A Korea. 
closer look at the assemblages, however, would find a variety of small tools that cannot simply be characterized as "crude" or "informal," as I present below.

The main assumption behind the notion of an unchanging crude lithic technology is that crude-looking artifacts were the unavoidable outcome of the reliance on coarse materials. Intensive analyses of lithic technology have been rarely conducted, and the a priori assumption of an unchanging lithic technology was one of the main obstacles in establishing a different chronological sequence. This simple deterministic relationship between the coarseness of raw material and the crudeness of artifacts may be inadequate in the face of significant variation in the quality of raw materials used to make lithic artifacts of various forms and size. The present study attempts to emphasize this point, focusing on the varieties of raw materials and their advantages in lithic technology, and variable raw material use in making different types of lithic artifacts.

\section{INTRODUCTION TO THE STUDY AREA}

The discovery and subsequent archaeological excavations at Chongokni signaled the beginning of Paleolithic research along the Imjin-Hantan River Valley where some 30 locations are known (Fig. 1). Most Imjin-Hantan Basin sites are located on large Pleistocene terrace deposits that formed on the basalt plain. The site of Juwol/Gawol-ri was discovered in 1988 and excavated by Seoul National University in 1993 (Matsufuji 1995; Yi and Lee 1993; Fig. 3). Although the site consists of two locations at different elevations, Juwol-ri and Gawol-ri are on the same massive Pleistocene terrace deposit along the Imjin River. The basalt bedrock underneath the deposit is much thinner and sporadic than that in the upper river valley, such as that found at Chongokni, suggesting that the extent of the basalt flow was limited toward the lower river basin (Yi and Lee 1993; Yi 2002).

Four test pits were excavated and four major stratigraphic units were identified from the deposits: alluvial gravel and sand, silty sand, silty clay, and top layers. Silty sand and silt were above the gravel and sand deposits, and contained only a few artifacts. The artifact-bearing silty clay is 2 to $3 \mathrm{~m}$ thick. Artifacts were sporadically collected, but mostly from the first Pleistocene layer beneath the humus. The Gawol-ri depositional profile demonstrates more obvious artifact concentration; the layer right beneath the humus contains the highest density of artifacts. The objects analyzed here are limited to those recovered from the upper horizon.

The Pyeongchang-ri site was excavated in advance of construction of a house complex. It is surrounded by mountains with 200 to $300 \mathrm{~m}$ peaks in the midcentral Korean Peninsula. It is on a Pleistocene terrace, mainly formed by fluvial deposits of braided streams and nearby tributaries of the Namhan River (Fig. 1). Two field seasons were conducted by Seoul National University, and $250 \mathrm{~m}^{2}$ was excavated. It is estimated that the Pleistocene deposit extends some $3000 \mathrm{~m}^{2}$ (Yi et al. 2000).

The stratigraphy of the deposit is relatively simple and shallow compared to that of large river terrace deposits at Juwol/Gawol-ri and Chongokni. The Pleistocene deposit is $150 \mathrm{~cm}$ thick, varying according to the elevation, and overlies the weathered granitic gneiss bedrock. Much of the upper portion of the deposit was destroyed by the construction work, and this is why we have a relatively large 


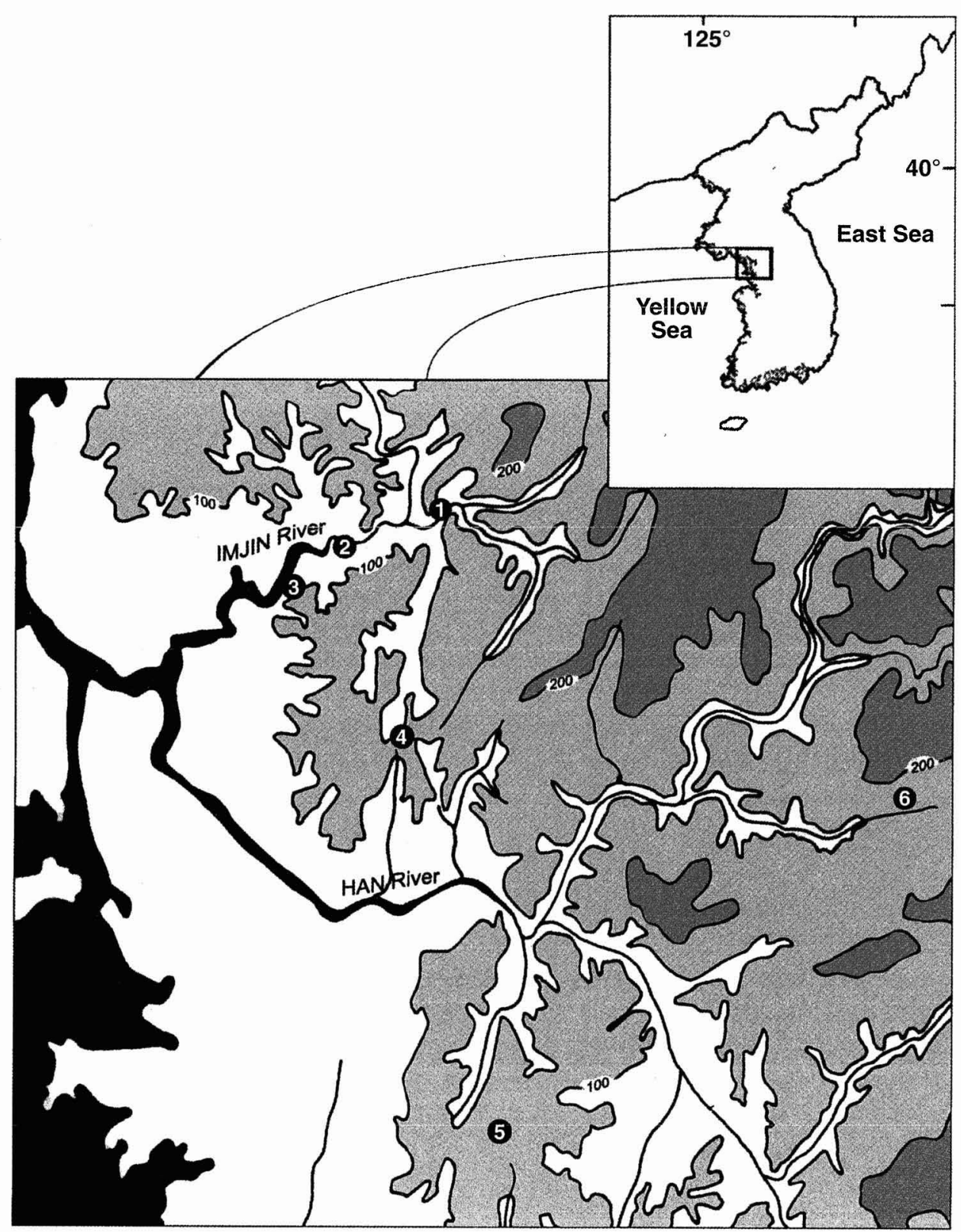

Fig. 1. Selected Paleolithic locations in the Middle Korean Peninsula: 1: Chongokni (Jeongok-ri, NICP 1983), 2: Juwol/Gawol-ri (Yi and Lee 1993), 3: Geumpari (Kumpari, NICP 1999), 4: Minrak-dong (Choi et al. 1996), 5: Pyeongchang-ri (Yi et al. 2000), 6: Hahwagye-ri (Choe et al. 1992).

amount of surface scatter artifacts. While distributed in a restricted area, the underlying sterile yellowish-brown layer yielded glass sherds of the Aira Tanzawa tephra, or AT, securely dated to 24,000-25,000 B.P. The layer may also be of eolian origin, indicating a cold and dry phase (Yi et al. 2000). 
The artifact-bearing layer of reddish brown clayey silt, some $100 \mathrm{~cm}$ thick, has basically the same texture and composition throughout, with distinctive vertical soil cracks. The cracks are 40 to $50 \mathrm{~cm}$ long and 1 to $2 \mathrm{~cm}$ wide, filled with yellowish-brown clay, revealing a horizontal tortoise structure. Chips (39.7 percent) and chunks (26.2 percent) constitute the bulk of the lithic collection, totaling 362 pieces of 549 excavated artifacts. Including cores and flakes in the debitage category, the count rises to 461 artifacts, comprising 82.1 percent of the collection. Artifacts classified as retouched pieces comprise 101 out of 685 total artifacts including those surface collected.

Paleolithic chronology in Korea is often controversial, exemplified by the disputes over the Chongokni assemblage (Bae 1988; Clark 1983; Kim and Bae 1983; Yi 1989, 1996). Most Imjin-Hantan locations were formed by similar processes under similar environments, characterized by deposition on the basalt bed dating to 300,000 to 500,000 years ago (Bae 1988, 2002; Yi 1989). While many consider that the sites were formed prior to the "Middle Paleolithic," some Late Paleolithic artifacts were also collected at Chongokni and Jangheung-ri (Choi B. 1999; Choi et al. 2001; Lee H. 1997). While it is possible that the deposition in most of the Imjin-Hantan locations started in the early Upper Pleistocene, the upper part of the deposit may be younger than 50,000 years. This depositional scenario seems reasonable, considering that the Chongokni date of 29,400 \pm 1900 fits well with the date suggested by the AT tephra discovery at roughly the same level as the deposit (Yi 1996). The existence of AT throughout the peninsula is reasonably well established (Choi and Sakada 1995; Eden et al. 1996; Soda 1999; Yi et al. 1998). For now, it is plausible that the lithic assemblages examined from Pyeongchang-ri and the upper part of the deposit of the Juwol-ri location can be dated to a comparable time period, the OIS 3 (Yi 2000).

Recent AT discoveries from Pleistocene locations throughout the peninsula raise more questions than they answer regarding the Korean Paleolithic, however. There are problems in accepting the date suggested by the AT, since the discovery seemingly contradicts previous chronological assumptions for the Korean Paleolithic. Most significantly, the AT discovery suggests that the informal crude technology (of which handaxes and choppers are main components) persisted until around 20,000 B.P. when industries characterized by the Upper Paleolithic blade technology had already been established in most parts of the Old World (Bae 1999:44-45; Bae et al. 1996:159-160; Yi 1996). Questioning the reliability of the chronometric dates, Bae (1999:45; NICP 1999) raises the possibility of the co-existence of contemporaneous cultural groups with crude assemblages and with blade technologies. The question can only be adequately answered when we examine the raw material quality and technology thoroughly. Again, the notion is largely based on the impressionistic observation of the coarse raw material in making stone artifacts without considering varieties and variable uses of the materials.

\section{QUARTZITE AND VEIN QUARTZ}

Quartzites and vein quartz are common rocks in the earth's crust. Being readily available in most regions and resistant to fracture damage, they were heavily exploited by prehistoric hunter-gatherers to make lithic artifacts in Korea as well as in Europe (e.g., Thacker 1996), Africa (Clark and Kleindienst 1974), and 
North America (Andrefsky 1998:226). While they are often regarded as one of the crudest lithic raw materials (e.g., Callahan 1979; Whittaker 1994), there has been little consideration of their properties and characteristics in lithic technology. The range of variety in raw material quality in making various lithic artifacts has not been thoroughly considered.

\section{Properties}

Quartzite is a general petrological term indicating metamorphosed sandstone mainly or entirely composed of quartz, a silica mineral. Various materials and individual quartz grains are welded together by an amorphous silica filling to form quartzite. The quartz content exceeds 90 percent in most quartzites, while some may have as much as 99 percent (Mottana et al. 1978). In other words, quartzite is basically an altered sandstone, "that has been recrystallized by the heat of volcanic activity occurring near the sediment or strengthened by silica filling the small spaces between grains" (Cotterell and Kamminga 1990:129). Generally, there are two varieties of quartzites in terms of metamorphism, metaquartzites and orthoquartzites, although it is often difficult to distinguish them. Orthoquartzites are varieties of sandstone that have not undergone metamorphosis. Quartz grains are interlocked and hardened by a cementing process in orthoquartzites, and fracture happens along the internal cement interstices between the individual quartz grains. If the grains are fine and there are few internal flaws, a more or less conchoidal fracture can be obtained. Metaquartzites represent metamorphosed sandstone in which particles of quartz were deformed and interlocked. Metaquartzite, "can be knapped across grains ... instead of breaking between the grains" (Whittaker 1994:72), with more easily controllable conchoidal fracturing properties (Andrefsky 1998:54-55).

Quartzites are widely distributed in Korea, especially in the mid-Peninsula (KGS 1999). Their weathered exterior surface is generally brownish but varies from reddish to yellowish, and the interior is also yellowish to reddish. While they vary in texture and hardness, fine-grained hard quartzites largely produce conchoidal fractures. Because they are hard and tough and the flake edge is durable such that it, "could stand up to rough usage on resistant materials" (Clark and Kleindienst 1974:104), quartzite cobbles and angular blocks were heavily used for making stone artifacts from the earliest Paleolithic period.

Also widely distributed and used for chipped stone tool manufacture are varieties of vein quartz. Vein quartz often occurs embedded in decomposed igneous rock. Since the quartz is hard and resists the natural weathering process, embedded vein quartz blocks and boulders are available as surrounding rocks decompose. The color is highly variable: semi-transparent white, light gray, yellow, and red. Vein quartz suitable for making stone artifacts occurs as outcrops and erratic boulders, or sometimes as scatters on and below the ground. As in quartzites, there may be varying amounts of impurities, internal flaws, and bedding planes along which breakage occurs, causing errors in knapping. A vein quartz nodule breaks relatively easily along its internal planes, producing a finer and sharper edge that can also be retouched.

Along with granular texture, homogeneity and internal planes affect the breakage pattern in both quartzites and vein quartz. Crystalline quartz has established 
Table i. Raw Material Grade Ranked by the Ease of Knapping

\begin{tabular}{lcl}
\hline CHARACTERISTIC & GRADE & \multicolumn{1}{c}{ SUgGeSTED materials } \\
\hline Soft & 0.5 & Ice, opal, some cold asphalts \\
Brittle & 1.0 & Good obsidian glass, some opalites \\
& 1.5 & Coarse obsidian \\
\multirow{3}{*}{ Strong } & 2.0 & Fine-grained basalt \\
& 2.5 & Heated fine-grained flints and cherts \\
& 3.0 & Finest flints and cherts \\
Tough & 3.5 & Most lithic materials: cherts, flints, jasper, chalcedonies, \\
& 4.0 & petrified wood, silicified shale \\
& & Coarser cherts, quartz crystal, agate, siltstone, silicified \\
& 4.5 & slate, siliceous limestone \\
& 5.0 & Come quartzites and rhyolites, argillite \\
& 5.5 & Coarse quartzite, coarse rhyolites, felsites, common basalt \\
\hline
\end{tabular}

Note: modified based on Callahan 1979:16 and Whittaker 1994:66.

planes of fracture, and it breaks along these planes, preventing conchoidal fracture as seen in pure glass, which consists of noncrystalline or amorphous silica, for example, obsidian or natural glass. Abundant internal flaws in polycrystalline quartz "have a great influence on the path of the fracture" (Cotterell and Kamminga $1990: 129)$.

Coarser grained quartzites and vein quartz with internal flaws generally do not allow the flaking to be controlled as easily as cryptocrystalline rocks such as chert and obsidian. Table 1 shows the grade scale of raw material types according to ease of working (Callahan 1979; Whittaker 1994). As expected, obsidian is the best material to work in lithic manufacture because of its homogeneity and amorphous crystalline structure. The next variety that could be easily worked in lithic manufacture is chert or flint, which is harder and more difficult to break than obsidian (Whittaker 1994:66). Quartzite represents one of the toughest materials to work, with a granular texture producing uneven fracture surfaces.

\section{Varieties and Artifact Types}

Prehistoric hunter-gatherers may have exploited different raw material types in various and patterned ways for lithic manufacture. Korean Paleolithic assemblages show that quartzite cobbles were widely used for making "large-cutting tools," 3 as demonstrated by artifacts from Chongokni and other Imjin Basin sites (Kim and Chung 1979; NICP 1983, 1999). This is because a tough and durable edge can be produced that is suitable for carrying out the work of large tools. It is used also because hard quartzite has a relatively homogeneous texture with few internal cracks and impurities. Handaxes, cleavers, and large knives were either made from a cobble as core tools or from a large flake (Fig. 2). In addition, among heavy-duty tool types, as defined by Clark and Kleindienst (1974), picks were almost exclusively made of metamorphosed quartzite sandstone in Korea.

Quartzite cobbles and blocks were also selected to make "heavy-duty tools," as 

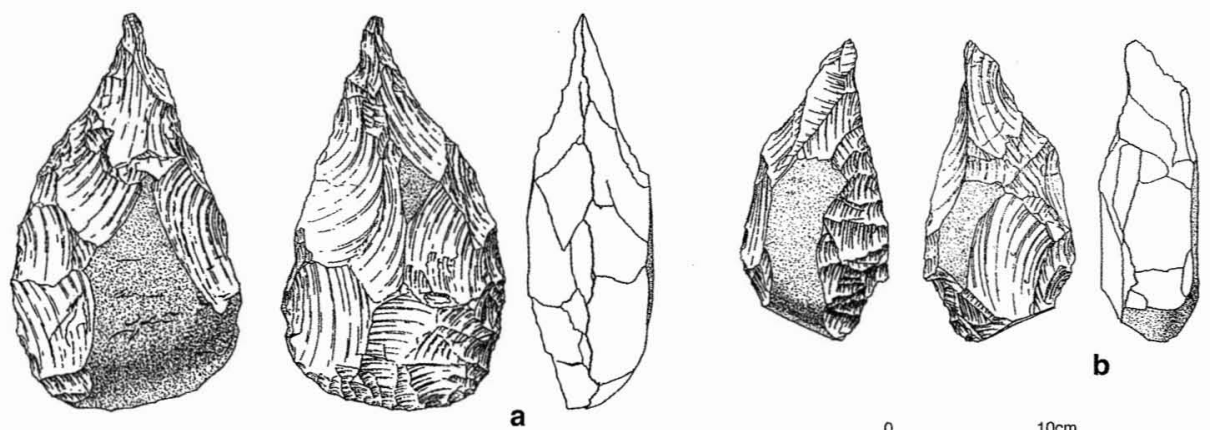

b

$10 \mathrm{~cm}$
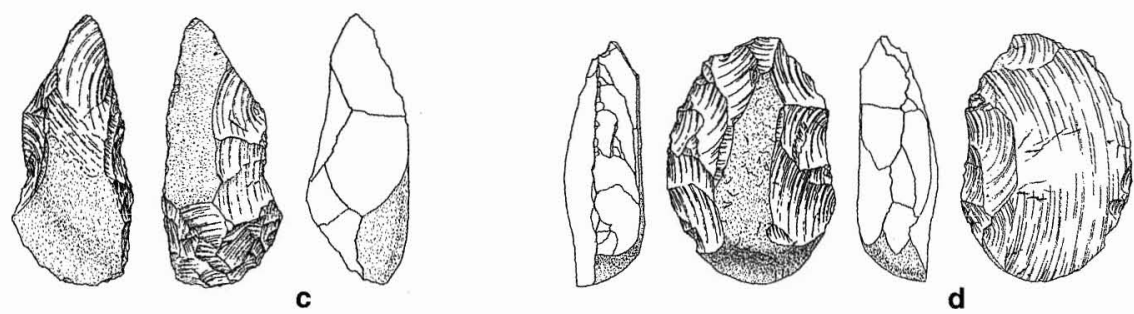

d

Fig. 2. Examples of artifacts made of quartzite cobbles from Juwol/Gawol-ri: a-b: handaxes, c: pick, d: knife/handaxe.

were sizable vein quartz nodules. In contrast, it is difficult to work vein quartz into large cutting tools, such as handaxes and cleavers, because it often contains internal flaws. Quartzites were not extensively used for making small tools; there are a limited number of quartzite scrapers, points, and small utilized flakes. Instead, angular blocks of vein quartz were commonly flaked into small tools; it produces a sharp edge when flaked and the edge could be retouched into various types of small artifacts (Fig. 3). The example in Figure 4 shows that even microblades were detached from a regular quartz rock. Although it was not regularly used for making microblade cores, the "advanced" flaking method such as pressure or indirect punch technique could be applied to this raw material type (Seong 1998).

The existing literature on the Korean Paleolithic has underrepresented the variation in the quality of quartzite and vein quartz for producing lithic artifacts of various forms and sizes. Although they are generally coarse, some varieties have a fine-grained texture and fracture conchoidally, appropriate for making sophisticated lithic artifacts. Because fracture occurs generally along the cemented silica between the quartz grains, conchoidal fracture depends largely upon how finegrained and pure the material is. Therefore, it is reasonable to divide the rock quality according to texture and distinguish the fine-grained variety from coarsegrained quartzites. Although the difference is gradual and continuous rather than discrete in a strict sense, it is usually straightforward in practice to distinguish finegrained varieties from coarse-grained ones with observable internal flaws. An approximate determination of texture and the amount of impurities and internal flaws contained in the material can generally be made with the naked eye. 


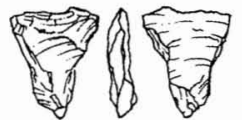

a
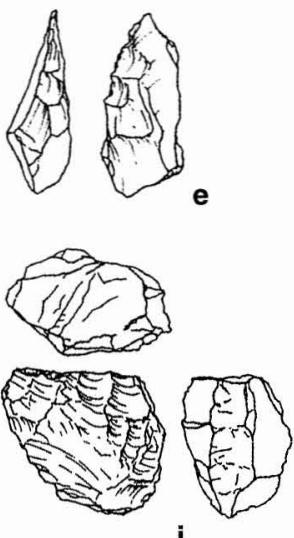

i
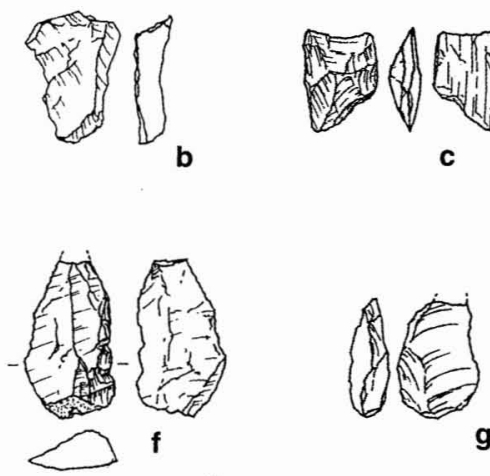

g
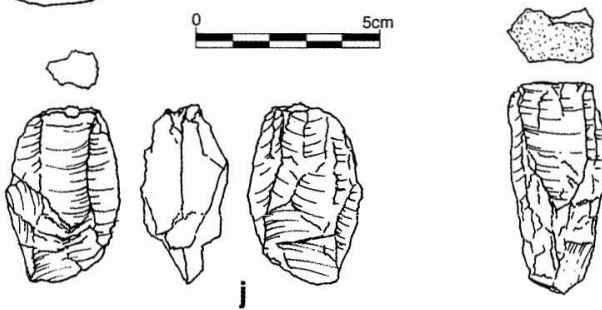
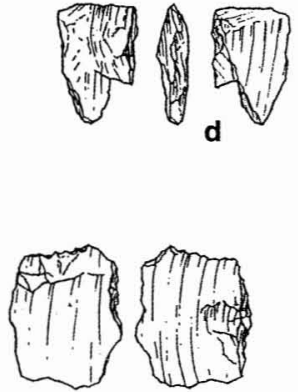

h

Fig. 3. Small tools made of quartzite and vein quartz: a, b: trapezoids from Chongokni, $c$, d: trapezoids from Pyeongchang-ri, e: backed knives from Juwol/Gawol-ri, f, g: backed knives from Pyeongchang-ri, i: pseudo-prismatic cores from Pyeongchang-ri, $\mathrm{j}$, k: pseudo-prismatic cores from Chongokni.
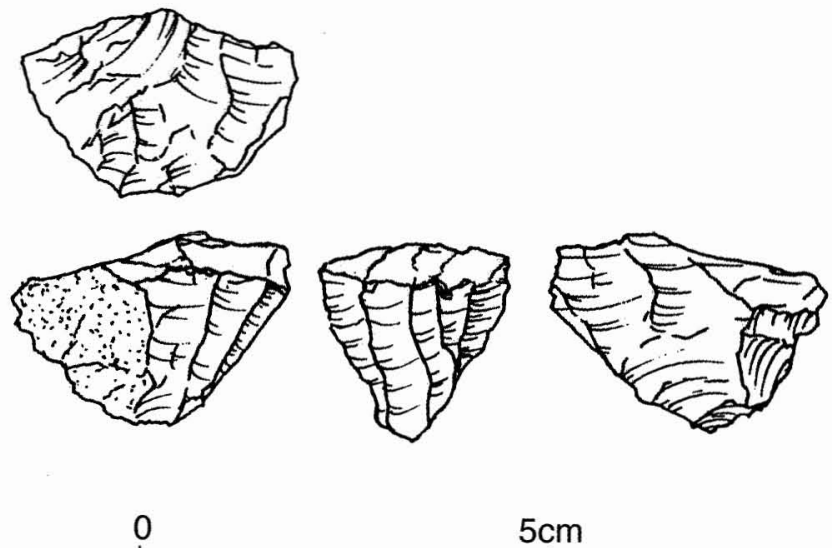

$5 \mathrm{~cm}$

Fig. 4. A rare microblade core made of quartz rock from Hahwagye-ri in the mid-Korean Peninsula. Blade and microblade manufacture with quartzite and vein quartz is difficult but not impossible, as this example shows. Quartzite and vein quartz were occasionally used in formalized lithic technology when finer grained material was not available or when the cost for obtaining those materials was too high. 
USE OF LOCAL RAW MATERIALS

The main purpose of this analysis is to see if there was deliberate raw material selection among local quartzite and vein quartz varieties in making certain kinds of lithic artifacts. The rock quality of both materials is scaled into two varieties, fine and coarse grained, given that the texture and homogeneity are believed to be the determinant factor in fracture mechanics.

\section{Tool Types and Raw Material Selection}

The Pyeongchang-ri and Imjin-Hantan Basin quartzite and vein quartz artifact collections show a significant number of small retouched pieces and cores, such as backed knives, trapezoids, and conical and pseudo-prismatic cores (Seong 2001; Yi et al. 2000). The analysis attempts to draw associations between artifact size, form, and raw material quality. Figure 5 and Table 2 show material qualities among the Pyeongchang-ri tool collection, and two aspects are recognizable. First, smaller tools tend to have been made of fine-grained varieties. The relationship between quality of raw material and weight is significant at the 0.05 significance level, as is the association between material and length or thickness. ${ }^{4}$ It is reasonable to conclude that better quality materials were selected to make smaller tools.

Second, the fine-grained variety has a higher length/width ratio than coarsegrained materials as illustrated in Figure 6. But the correlation between the elongation and quality of the raw material is not apparent, and such correlation is not observable in terms of relative thickness. The correlation is not represented by the statistical summary shown in Table 2 , and this is probably because there are some outliers in both categories. It may also be due to the fact that the difference is not evident.

Another important point is that the quality of raw material is related to tool type and size, reflecting variable use of different raw materials. In other words, making certain tool types may require better quality materials, as Table 3 illustrates. As expected, no choppers from Pyeonchang-ri were made of fine-textured materials, and one specimen was made of very coarse quartzitic sandstone. This is because the main concern when making choppers must have been robustness of the material.

Besides choppers, notches are the most consistent in terms of raw material quality: all nine specimens were made of generally coarse varieties. The tendency of using poorer materials in making notches closely matches the study of Western European Middle Paleolithic data. In Europe, it is suggested that the opportunistic nature of manufacture and the use of such tool types as notches and denticulates are reflected by the use of generally lower-grade raw materials (Geneste 1985 in Mellars 1996:137-138). Notches from Pyeongchang-ri also have highly variable form and size with little evidence of standardization, which is also paralleled in the European cases (Debénath and Dibble 1994). But, among six denticulates collected at Pyeongchang-ri, three were made of high-quality raw material and the other three were made of poorer quality material. So, the Pyeonchang-ri denticulates do not conform to the same pattern as the European cases. Given the small sample size, however, it is premature to compare the pattern between the two regions. 


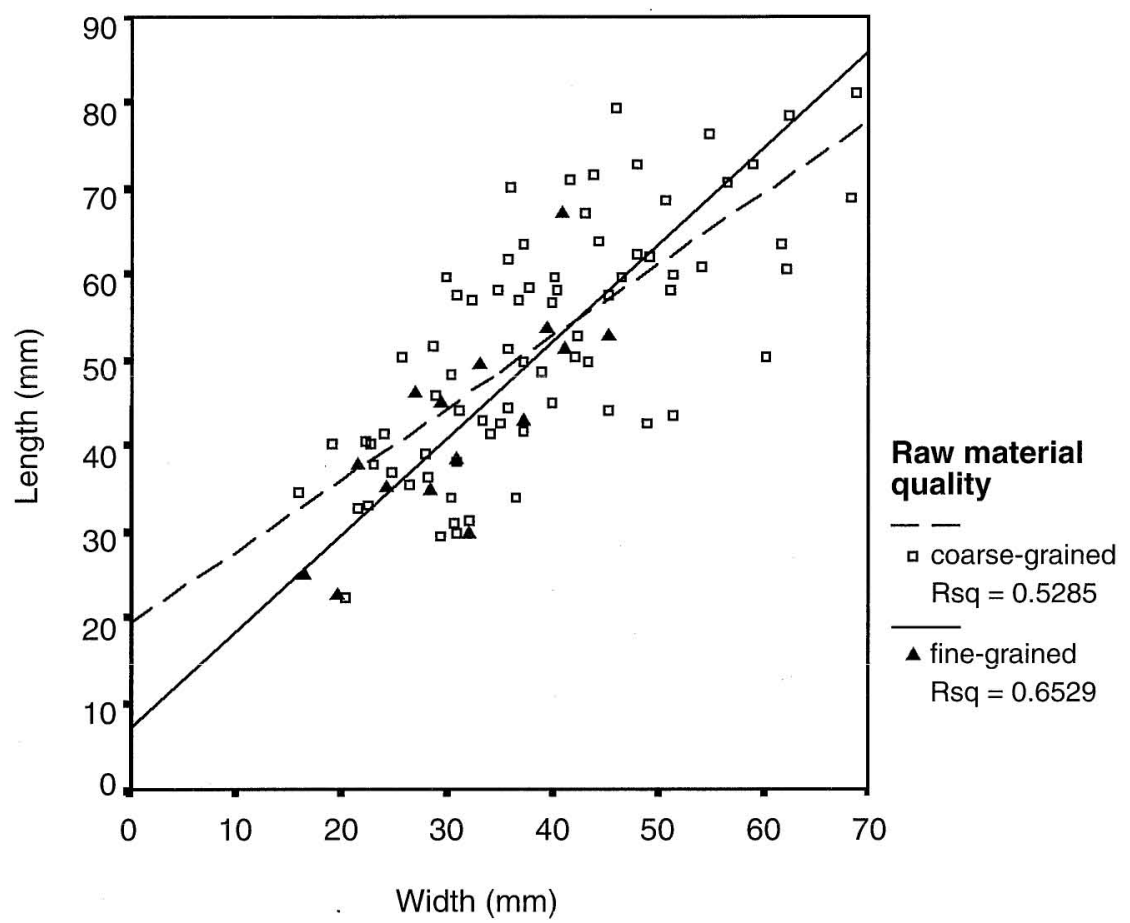

Fig. 5. Raw material quality and tool size of the Pyeongchang-ri collection. Choppers were not considered because they are larger than other tool types. Choppers were all made of coarse-grained materials.

Thick scrapers (or rabots), scrapers, small scrapers, points, and awls from Pyeongchang-ri all show that they were largely made without consideration of raw material quality. A small number of specimens of these tool types were made of better quality raw material, but most were made of coarse-grained varieties.

Although there are handful of trapezoids and backed knives, they tend to be made of better quality materials than other tool types. There are two exceptions

Table 2. Quality Differences in Pyeongchang-Ri Tools Excluding Choppers

\begin{tabular}{|c|c|c|c|c|c|c|}
\hline QUALITY & $\begin{array}{c}\text { STAT. } \\
\text { CATEGORY }\end{array}$ & $\begin{array}{l}\text { LENGTH } \\
(\mathrm{MM})\end{array}$ & $\begin{array}{l}\text { WIDTH } \\
\text { (мM) }\end{array}$ & $\begin{array}{l}\text { THICKNESS } \\
\text { (MM) }\end{array}$ & LENGTH/WIDTH & $\begin{array}{l}\text { WEIGHT } \\
\text { (G) }\end{array}$ \\
\hline \multirow[t]{3}{*}{ Fine-grained } & Mean & 42.12 & 31.09 & 18.17 & 1.37 & 29.56 \\
\hline & $\mathrm{N}$ & 15 & 15 & 15 & 15 & 15 \\
\hline & Std. D. & 11.89 & 8.54 & 9.12 & .24 & 24.67 \\
\hline \multirow[t]{3}{*}{ Coarse-grained } & Mean & 51.77 & 38.82 & 23.66 & 1.38 & 58.37 \\
\hline & $\mathrm{N}$ & 75 & 75 & 75 & 75 & 75 \\
\hline & Std. D. & 13.97 & 12.19 & 9.03 & .31 & 48.50 \\
\hline \multirow[t]{3}{*}{ Total } & Mean & 50.16 & 37.53 & 22.74 & 1.38 & 53.57 \\
\hline & $\mathrm{N}$ & 90 & 90 & 90 & 90 & 90 \\
\hline & Std. D. & 14.06 & 11.97 & 9.23 & .30 & 46.56 \\
\hline
\end{tabular}

Note: Tools made of fine-grained quartzites and vein quartz tend to be smaller than those made of coarse-grained varieties. 
Table 3. Quality Differences Across the Tool Types of the Pyeongchang-ri Collection

\begin{tabular}{|c|c|c|c|c|c|c|c|c|c|c|c|c|}
\hline QUALITY & CHOPPER & $\begin{array}{c}\text { THICK } \\
\text { SCRAPER }\end{array}$ & SCRAPER & $\begin{array}{l}\text { SMALL } \\
\text { SCRAPER }\end{array}$ & POINT & $A W L$ & NOTCH & $\begin{array}{l}\text { DENTICU- } \\
\text { LATE }\end{array}$ & TRAPEZOID & $\begin{array}{c}\text { BACKED } \\
\text { KNIFE }\end{array}$ & OTHER & TOTAL \\
\hline Fine-grained & 0 & $\begin{array}{c}2 \\
(14.3)\end{array}$ & $\begin{array}{c}2 \\
(10.5)\end{array}$ & $\begin{array}{c}3 \\
(17.6)\end{array}$ & $\begin{array}{c}1 \\
(20.0)\end{array}$ & $\begin{array}{c}1 \\
(16.7)\end{array}$ & $\begin{array}{c}0 \\
(0)\end{array}$ & $\begin{array}{c}3 \\
(50.0)\end{array}$ & $\begin{array}{c}2 \\
(28.6)\end{array}$ & $\begin{array}{c}2 \\
(33.3)\end{array}$ & 1 & 17 \\
\hline Coarse-grained & 11 & 12 & 16 & 14 & 4 & 5 & 9 & 3 & 5 & 4 & 1 & 84 \\
\hline Total & 11 & 14 & 18 & 17 & 5 & 6 & 9 & 6 & 7 & 6 & 2 & 101 \\
\hline
\end{tabular}

Note: Numbers in parenthesis in fine-grained category represent percentile changed by fine-grained variety among the total artifacts of each tool type. 
in the backed knives category that are made of low-quality raw material, but these may be better classified as retouched flakes. The reason why trapezoids and backed knives, often considered characteristic Upper Paleolithic types in Japan (e.g., Kajiwara 1999; Sato 1992), were made of better quality raw material is partly due to the requirement of a sharp working edge.

\section{Raw Material Selection for Cores and Flakes}

Raw material selection as suggested by the tool form and size is also supported by the Pyeongchang-ri and Juwol/Gawol-ri flake collections. Flakes analyzed here are limited to complete flakes, excluding broken pieces and flake fragments, as categorized by Sullivan and Rozen (1985; Rozen and Sullivan 1989). Aside from the sample size issue, there seems to be a difference in raw material quality in core types from the Geumpa-ri and Chongokni collections. Polyhedral cores from Chongokni and Geumpa-ri were dominantly made of poor-quality varieties. On the other hand, a few cores with elongated flake scars were made of high-quality material in the Chongokni collection (Fig. 3k, j). This may suggest that smaller and "pseudo-prismatic" elongated cores tend to be made of higher-grade raw material than casual and polyhedral cores.

The semiprismatic core technique was mainly used for producing elongated flakes. As Tables 4 and 5 and Figure 6 show, although flakes of fine-grained material tend to have a higher length/width ratio, the difference is not significant. However, most statistical categories do show that there are significant differences in flake dimensions between flakes made of higher-grade varieties and those of coarse-grained variety, i.e., one is smaller than the other. The collections of Pyeongchang-ri and Juwol/Gawol-ri show a diminution of size toward better quality material flakes. No difference in the dimensions of flakes made of highquality material between the two collections is detected.

Flakes made of fine-grained materials are shorter and narrower than coarsegrained flakes by more than $10 \mathrm{~mm}$ in both length and width, and they are also thinner by some $4 \mathrm{~mm}$ (Tables 4 and 5 ). The difference is also clearly reflected in the measurement of weight: flakes of fine-grained material averaged around $10 \mathrm{~g}$

Table 4. Summary Statistics for Quality of Raw Material Observed on Complete Flakes from Pyeongchang-Ri

\begin{tabular}{|c|c|c|c|c|c|c|c|c|c|}
\hline QUALITY & $\begin{array}{c}\text { STAT. } \\
\text { CATEGORY }\end{array}$ & $\begin{array}{l}\text { LENGTH } \\
\text { (MM) }\end{array}$ & $\begin{array}{l}\text { WIDTH } \\
\text { (MM) }\end{array}$ & $\begin{array}{c}\text { THICK- } \\
\text { NESS } \\
\text { (MM) }\end{array}$ & $\begin{array}{c}\text { PLATFORM } \\
\text { LENGTH } \\
(M M)\end{array}$ & $\begin{array}{c}\text { PLATFORM } \\
\text { WIDTH } \\
(M M)\end{array}$ & $\begin{array}{l}\text { DORSAL } \\
\text { SCAR } \\
\text { COUNT }\end{array}$ & $\begin{array}{c}\text { LENGTH/ } \\
\text { WIDTH }\end{array}$ & $\begin{array}{l}\text { WEIGHT } \\
\text { (G) }\end{array}$ \\
\hline \multirow{3}{*}{$\begin{array}{l}\text { Fine- } \\
\text { grained }\end{array}$} & Mean & 33.90 & 26.13 & 12.14 & 21.56 & 11.09 & 2.60 & 1.40 & 10.42 \\
\hline & $\mathrm{N}$ & 7 & 7 & 7 & 7 & 7 & 5 & 7 & 6 \\
\hline & Std. D. & 8.44 & 10.41 & 4.26 & 8.58 & 5.15 & 2.19 & .37 & 6.96 \\
\hline \multirow{3}{*}{$\begin{array}{l}\text { Coarse- } \\
\text { grained }\end{array}$} & Mean & 45.84 & 35.79 & 16.99 & 25.11 & 12.80 & 2.17 & 1.35 & 27.68 \\
\hline & $\mathrm{N}$ & 39 & 39 & 39 & 39 & 39 & 35 & 39 & 38 \\
\hline & Std. D. & 12.85 & 9.79 & 4.22 & 9.12 & 5.32 & 1.07 & .48 & 18.07 \\
\hline \multirow[t]{3}{*}{ Total } & Mean & 44.03 & 34.32 & 16.25 & 24.57 & 12.54 & 2.23 & 1.36 & 25.33 \\
\hline & $\mathrm{N}$ & 46 & 46 & 46 & 46 & 46 & 40 & 46 & 44 \\
\hline & Std. D. & 12.95 & 10.38 & 4.54 & 9.04 & 5.28 & 1.23 & .46 & 17.96 \\
\hline
\end{tabular}


Table 5. Summary Statistics for Quality of Raw Material Observed on Complete Flakes from Juwol/Gawol-ri

\begin{tabular}{|c|c|c|c|c|c|c|c|c|c|}
\hline QUALITY & $\begin{array}{c}\text { STAT. } \\
\text { CATEGORY }\end{array}$ & $\begin{array}{l}\text { LENGTH } \\
\text { (MM) }\end{array}$ & $\begin{array}{l}\text { WIDTH } \\
\text { (MM) }\end{array}$ & $\begin{array}{l}\text { THICKNESS } \\
\text { (MM) }\end{array}$ & $\begin{array}{c}\text { PLATFORM } \\
\text { LENGTH } \\
(\mathrm{MM})\end{array}$ & $\begin{array}{c}\text { PLATFORM } \\
\text { WIDTH } \\
\text { (MM) }\end{array}$ & $\begin{array}{c}\text { DORSAL } \\
\text { SCAR } \\
\text { COUNT }\end{array}$ & $\begin{array}{c}\text { LENGTH/ } \\
\text { WIDTH }\end{array}$ & $\begin{array}{c}\text { WEIGHT } \\
\text { (G) }\end{array}$ \\
\hline \multirow{3}{*}{$\begin{array}{l}\text { Fine- } \\
\text { grained }\end{array}$} & Mean & 32.83 & 25.70 & 10.93 & 18.06 & 7.94 & 2.50 & 1.31 & 9.44 \\
\hline & $\mathrm{N}$ & 7 & 8 & 8 & 8 & 8 & 8 & 8 & 7 \\
\hline & Std. D. & 8.14 & 10.39 & 3.86 & 9.26 & 4.84 & 1.31 & .39 & 5.55 \\
\hline \multirow{3}{*}{$\begin{array}{l}\text { Coarse- } \\
\text { grained }\end{array}$} & Mean & 47.10 & 38.43 & 14.88 & 27.47 & 10.99 & 1.86 & 1.28 & 40.75 \\
\hline & $\mathrm{N}$ & 20 & 23 & 23 & 23 & 22 & 21 & 23 & 22 \\
\hline & Std. D. & 13.46 & 18.33 & 7.18 & 14.99 & 4.96 & .91 & .39 & 56.14 \\
\hline \multirow[t]{3}{*}{ Total } & Mean & 43.40 & 35.15 & 13.86 & 25.05 & 10.18 & 2.03 & 1.29 & 33.19 \\
\hline & $\mathrm{N}$ & 27 & 31 & 31 & 31 & 30 & 29 & 31 & 29 \\
\hline & Std. D. & 13.72 & 17.43 & 6.66 & 14.23 & 5.04 & 1.05 & .38 & 50.56 \\
\hline
\end{tabular}

with a standard deviation of 5 to 7 in both the Pyeongchang-ri and Juwol/ Gawol-ri collections, while poor-quality material flakes averaged around $27 \mathrm{~g}$ and $40 \mathrm{~g}$ for each collection. The general diminution of size in flakes of high-quality raw material is paralleled by the same trend observed in tool size distribution and material quality.

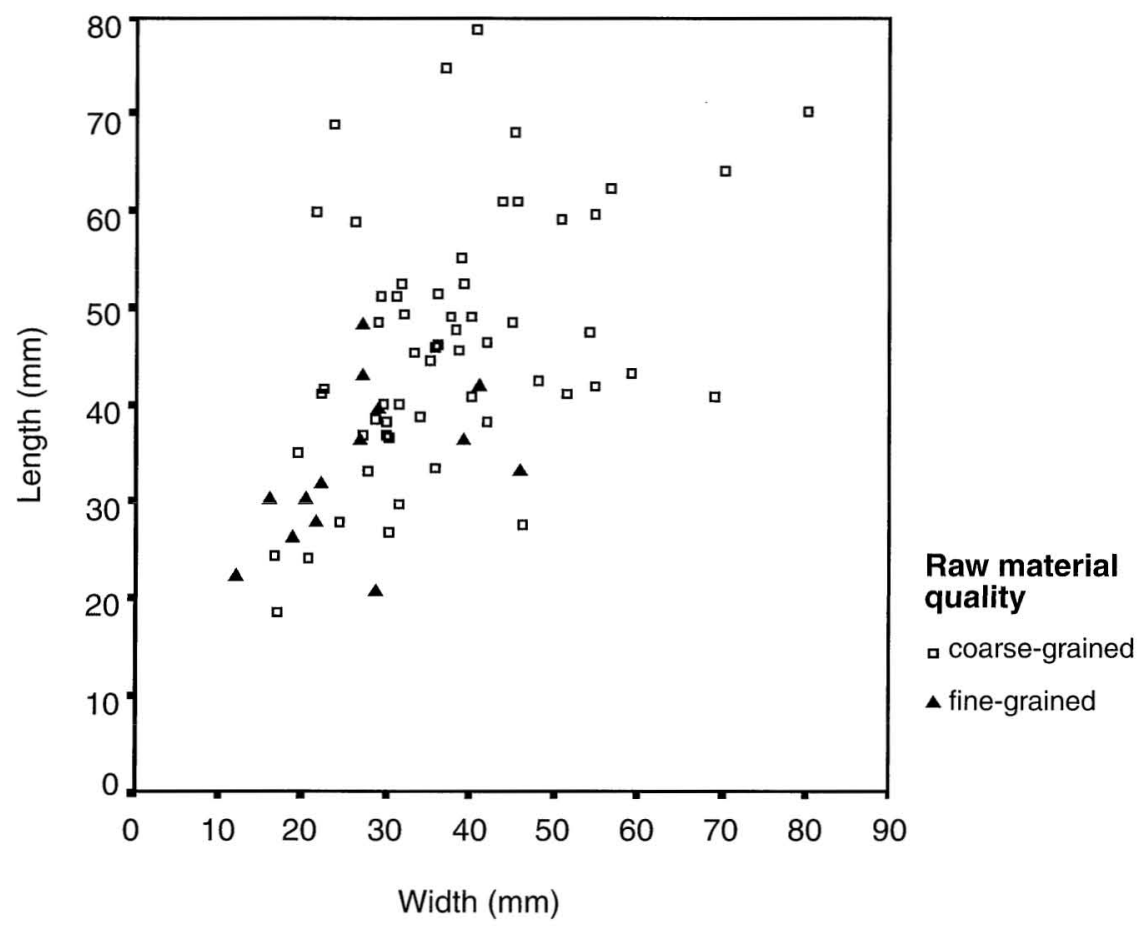

Fig. 6. Length-width distribution of complete flakes from Pyeongchang-ri and Juwol-ri in terms of the raw material quality. It is well illustrated that fine-grained flakes are generally smaller than flakes made from coarse-grained raw material. 
In addition to the size, flakes made of high-quality materials exhibit more dorsal scars (Table 4). An average of 2.6 dorsal scars is observed on the highquality flakes from Pyeongchang-ri, contrasting with 2.17 and 1.86 for coarsegrained flakes. Similar statistical results are obtained from the analysis of the Juwol/Gawol-ri flakes (2.50 versus 1.86, Tablè 5). Along with the size differences, significantly less cortical surface is seen on the high-quality flakes in both the Pyeongchang-ri and Juwol/Gawol-ri collections. Differences in size, cortex coverage, and dorsal scar count, which are generally related to reduction intensity, may suggest that fine-grained materials were more intensively exploited than coarse-grained varieties. The influence of raw material quality in reduction intensity fits well with case studies from other parts of the world (e.g., Andrefsky 1994, 1998; Rolland and Dibble 1990). At present, however, it is premature to discuss the influence of other factors, such as package size and site function, as exemplified by recent European Paleolithic studies (e.g., Kuhn 1991, 1992, 1995).

\section{Raw Material Change}

The Pyeongchang-ri collection and other quartzite and vein quartz assemblages include a significant number of tools and cores that can be considered examples of "formal" artifacts of the Late Paleolithic, for example backed knives and trapezoids (Seong 2001; Yi et al. 2000). In other words, using local quartzite and quartz cobbles and blocks was an effective strategy in lithic manufacture as long as a suitable reduction technology was available. The lithic technology may be characterized as a flexible strategy incorporating the demand to make smaller and more sophisticated artifacts by selecting local rock varieties. Some pseudoprismatic cores of generally higher grade material show that the raw materials were used to detach elongated flakes, while only limited work was exerted in platform preparation. The above discussion emphasizes the nature of a wide variety of local raw materials being used in contrast to the conventional assumption of coarse material. Fine-grained varieties were effectively used in making small tools, such as trapezoids and backed knives, from flakes and cores of elongated forms.

However, the above discussion does not argue that local quartzite and vein quartz varieties possess the necessary and sufficient properties to make every kind of formalized artifact. The selective use of local materials necessarily reaches the point of raw material constraint. It is expected that the use of local raw material varieties steadily developed until there was an overwhelming need to secure finegrained cryptocrystalline rocks even from a distance, as suggested by the transition to the blade and microblade industry in the Late Paleolithic. While effective in making various small artifacts as presented thus far, local quartzite and vein quartz varieties are generally not suitable for systematic production of blades and microblades.

Systematic manufacture of blades and microblades requires significant work in preparing cores, which must have led to many failures, even with high-quality quartz rocks. If blades and microliths were required, a more effective strategy must have been to acquire cryptocrystalline materials from distant sources, which in turn may explain the Late Paleolithic transition. Most blades and microblades 
were made of cryptocrystalline rocks such as obsidian and siliceous tuff. Stone tool makers in the final Pleistocene turned to new raw materials, which were often obtained from a distance, especially in the middle Korean Peninsula. Nevertheless, the manifestation of a formalized (blade and microblade) technology from local raw materials is always the preferred option, given the negligible cost in securing the materials. This is exemplified by occasional quartzite and vein quartz blades (microblades) and blade cores in the collection, as demonstrated in Figure 4.

In sum, the above discussion emphasizes the following points. First, we should not overlook the significant range of variation in lithic raw materials, which has traditionally been characterized simply as being "coarse." Second, these materials are as tough and robust as they are coarse, providing durable and strong working edges. Third, most types of lithic artifacts can efficiently be made of quartz rocks, except for some later Paleolithic types, such as blades and microblades.

\section{CONCLUSIONS AND IMPLICATIONS}

Paleolithic research in Korea is hampered by the lack of a reliable descriptive and analytical framework. Despite a growing quantity of archaeological data during the last two decades, impressionistic assumptions still prevail. Traditionally, there have been few, if any, attempts to examine the raw material properties and varieties of quartzite and vein quartz lithic technology under consideration here. This was mainly because of the assumption that these raw materials lack appropriate fracturing properties for making lithic artifacts.

Because of internal planes and flaws, it is often difficult to flake quartzite and vein quartz into tools of suitable shape and size. However, since fracture happens along the amorphous silica cement between quartz grains and even across quartz particles in some varieties, fine-grained materials without major internal flaws show largely conchoidal fracture. Even though the raw material may be one of the crudest materials in lithic manufacture, there may be good quality stone mass and/or fine-grained parts within a single block of quartz rock. Such materials may be selectively used for making small tools, since they are as tough as they are crude.

The analyses of Pyeongchang-ri and other assemblages from the middle Korean Peninsula show a variable use of local raw materials to make artifacts of different forms and size. Thus, current assumptions of a simple and deterministic relationship between coarseness of the raw material and crude lithic technology may disguise a significant range of lithic variability and change.

\section{ACKNOWLEDGMENTS}

The arguments in this paper were developed from my dissertation research at the University of Washington. I thank my supervisory committee, Professors Karl Hutterer, Donald Grayson, and Matsuo Tsukada. Dr. Miriam Stark and two anonymous reviewers read the previous draft and made valuable comments of which I am very grateful. I would also like to express my appreciation of help from Dr. Seonbok Yi and Yongwook Yoo during my dissertation research in Korea. This work was supported by a Korea Research Foundation Grant (KRF-2001-037-BA0035). 


\section{NOTES}

1. Donggwanjin was the first Paleolithic site discovered in Korea in 1935 by a Japanese scholar.

2. Bae (1988) and Yi (1998) instead adopted the East African Paleolithic typology devised by Clark and Kleindienst (1974) for the Kalambo Falls site and later refined by Isaac (1977), employing a general distinction of large, heavy, and small tools.

3. Large tools of more than $10 \mathrm{~cm}$ in length with a sharp edge, such as handaxes, cleavers, and large knives, as defined by Clark and Kleindienst (1974).

4. Since weight, length, and thickness are highly correlated among themselves, the following analysis is limited to the correlation between raw material and weight, one of the most reliable measurements on lithic artifacts (Shott 1994).

\section{REFERENCES CITED}

ANDREFSKY JR., W.

1994 Raw material availability and the organization of technology. American Antiquity 59:2135.

1998 Lithics: Macroscopic Approaches to Analysis. Cambridge: Cambridge University Press.

BAE, K.

1988 The Significance of Chongokni Industry in the Tradition of the Palaeolithic Culture in East Asia. Ph.D. diss., Department of Anthropology, University of California, Berkeley.

1997 Paleolithic chronology, in Hanguksa 2: Paleolithic and Neolithic Culture: 13-40, assembled and published by Kuksa-pyeonchan-wiwonhoe (Committee of Korean History Publications). Seoul: Kuksa-pyeonchan-wiwonhoe (in Korean).

1999 The Paleolithic site of Naechon-ri, Jinju, in Paleolithic Culture of Yeongnam, Collected Papers Presented at the $8^{\text {th }}$ Symposium of the Yeongnam Archaeological Society: 31-46. Busan: Yeongnam Archaeological Society (in Korean).

2002 Chongokni Paleolithic site: Current understandings. Paper presented at the International Seminar for Commemorating the Chongokni Paleolithic Site. Yeoncheon, Korea.

Bae, K., H. Lee, Y. Sin, S. Hwang, and Y. OH

1996 Report of Excavation of the Chongokni Paleolithic Site, 1994-1995. Department of Anthropology, Hanyang University, Seoul (in Korean).

Callahan, E.

1979 The basics of biface knapping in the eastern fluted point tradition: A manual for flintknappers and lithic analysts. Archaeology of Eastern North America 7(1):1-180.

Choe, B. K., Y. B. Kim, And N. D. Kim

1992 An excavation report of the Hahwagye-ri Mesolithic site. In Excavations of Archaeological Sites in the Construction Area of Jungang Highway: 13-244. Assembled by Kangwon National University Museum. Chuncheon: Kangwon-do (in Korean).

Choi, B.

1999 Jangheung-ri Paleolithic site. Journal of Korean Prehistoric Archaeological Society 6:107-114 (in Korean).

Choi, B., S. Choe, S. Choe, H. Lee, and J. Cha

2001 The Jangheung-ri Paleolithic Site. Chuncheon: Institute of Kangwon Archaeology (in Korean).

Choi, M. L., S. Yi, AND J. T. Choi

1996 Excavation Report on Minrak-dong Site. Seoul National University Museum and Korea Land Corporation.

Choi, S. R., and K. Sakada

1995 A study of volcanic tephra remains in the southern coastal region in Korean and their relevance for the chronology of prehistoric sites. In Rediscovery of History: 97-145, edited by Hallim Science Academy. Chuncheon: Sohwa (in Korean).

Chung, Y.

1997 Paleolithic artifacts, in Hanguksa 2: Paleolithic and Neolithic Culture: 137-223, assembled and published by Kuksa-pyeonchan-wiwonhoe (Committee of Korean History Publications). Seoul: Kuksa-pyeonchan-wiwonhoe (in Korean). 
Clark, J. D.

1983 Report on a visit to Paleolithic sites in Korea, in Chongokni: An Excavation Report: 594598, assembled and published by National Institute of Cultural Properties, Republic of Korea, Seoul.

Clark, J. D., and M. Kleindienst

1974 The Stone Age cultural sequence: Terminology, typology and raw material, in Kalambo Falls Prehistoric Site, vol. 2:77-106, ed. J. D. Clark, et al. Cambridge: Cambridge University Press.

Cotterell, B., and J. Kamminga

1990 Mechanics of Pre-Industrial Technology. Cambridge: Cambridge University Press.

Debénath, A., and H. Dibble

1994 Handbook of Paleolithic Typology: Lower and Middle Paleolithic of Europe. Philadelphia: University Museum, University of Pennsylvania.

Eden, D. N., P. C. Froggatt, H. Zhen, and H. Machida

1996 Volcanic glass found in late Quaternary Chinese loess: A pioneer for future studies? Quaternary International 34-36:107-111.

Geneste, J.-M.

1985 Analyse Lithique d'Industries Mousteriénnes du Périgod: Une approache technolgique du comportement des groupes humains au Paléolithique moyen. Ph.D. diss., Universite de Bordeaux.

ISAAC, G. L.

1997 Olorgesailie: Archaeological Studies of a Middle Pleistocene Lake Basin in Kenya. Chicago: University of Chicago Press.

Kajiwara, H.

1999 "Opening remarks" for the Symposium to Commemorate the $80^{\text {th }}$ Birthday Celebrations of Professor Chosuke Serizawa, in World Views on the Early and Middle Paleolithic in Japan: 1-51, assembled by Tohoku Fukushi University, Japan.

KGS (Korean Geological Society)

1999 Geology of Korea. Seoul: Sigma Press (in Korean).

KIM, W., AND K. BAE

1983 Excavation by Seoul National University, in Chongokni: An Excavation Report: 1-173, assembled and published by NICP (National Institute of Cultural Properties, Korea), Seoul (in Korean).

Kim, W., AND Y. Chung

1979 A preliminary report of Chongokni Acheulian industry. Jindan Hakbo 46-47:5-56 (in Korean).

KPM (Kyonggi Provincial Museum)

2001 Imjin River Valley, Kyonggi Province: The Site Survey Report, vols. 2-3. Kyonggi Provincial Museum, Suwon, Korea (in Korean).

Kunn, S.

1991 "Unpacking" reduction: Lithic raw material economy in the Mousterian west-central Italy. Journal of Anthropological Archaeology 10:76-106.

1992 Blank form and reduction as determinants of Mousterian scraper morphology. American Antiquity 57(1): 115-128.

1995 Mousterian Lithic Technology: An Ecological Perspective. Princeton, New Jersey: Princeton University Press.

LEE, G.

1999 Tanged-points and associated artifacts, in Paleolithic Culture of Yeongnam: 83-96. Collected Papers Presented at the $8^{\text {th }}$ Symposium on the Archaeology of Yeongnam Region). Busan (Busan): Yeongnam Archaeological Society (in Korean).

2001 Paleolithic sites in the Honam region, in Paleolithic Culture in Korea: 247-262, assembled and published by Yonsei University Museum. Seoul (in Korean).

LEE, H.

1997 The meaning of the technical flake discovered at Chongokni. Hanguk Sanggosa Hakbo 25:7-19 (in Korean).

2000 A study of Middle Paleolithic Culture in Northeast Asia. Hanguk Sanggosa Hakbo 33:48 (in Korean). 
Matsufuji, K.

1995 A visitor's note on the Chongokni Paleolithic site. Paleolithic Archaeology 50:65-75 (in Japanese).

Mellars, P.

1996 The Neanderthal Legacy: An Archaeological Perspective from Western Europe. Princeton: Princeton University Press.

Mottana, A., R. Grespi, and G. Liborio

1978 Simon and Schuster's Guide to Rocks and Minerals. New York: Simon and Schuster.

NICP (National Institute of Cultural Properties, Republic of Korea)

1983 Chongokni: An Excavation Report. Assembled and published by NICP, Seoul (in Korean).

1999 Kumpari (Geumpa-ri) Paleolithic Site. Assembled and published by NICP, Seoul (in Korean).

PARK, Y.

2001 Analytical study of the lithic materials from the Middle Paleolithic cultural layers in southern Korea. Hanguk Guseokgi Hakbo 5:1-58.

Rolland, N., and H. L. Dibble

1990 A new synthesis of Middle Paleolithic variability. American Antiquity 55(3):480-499.

Rozen, K. C., ANd A. P. Sullivan III

1989 The nature of lithic reduction and lithic analysis: Stage typologies revised. American Antiquity 54(1): 179-184.

SATO, H.

1992 The Structure and Evolution of the Paleolithic in Japan. Tokyo: Hakusho (in Japanese).

SEONG, C.

1998 Microblade technology in Korea and adjacent Northeast Asia. Asian Perspectives $37(2): 245-278$.

2001 Raw Materials and Evolution of Lithic Technology in Upper Pleistocene Korea. Unpublished Ph.D. diss., University of Washington, Seattle.

Sнотт, M. J.

1994 Size and form in the analysis of flake debris: Review and recent approaches. Journal of Archaeological Method and Theory 1(1): 69-110.

SODA, T.

1999 Tephrochronological study of the Early and Middle Paleolithic in Japan. Paper presented at the Symposium to Commemorate the $80^{\text {th }}$ Birthday Celebrations of Professor Chosuke Serizawa, in World Views on the Early and Middle Paleolithic in Japan: 53-61, assembled by Tohoku Fukushi University, Japan.

SOHN, P.

1968 Sokchang-ni cobble chopper cultural layer. Hanguksa Youngu 1:1-62 (in Korean).

1970 Burin-endscraper cultural layer at Sokchang-ni. Hankuksa Younku 5:1-46 (in Korean).

1993 Sokchang-ni Prehistoric Site. Seoul: Donga-chulpansa (in Korean).

Sullivan III, A. P., And K. C. Rozen

1985 Debitage analysis and archaeological interpretation. American Antiquity 50(4):755-779.

THACKER, P. T.

1996 Hunter-gatherer lithic economy and settlement systems, in Stone Tools: Theoretical Insights into Huinan Prehistory: 101-124, ed. G. H. Odell. New York: Plenum Press.

WhitTAKer, J. C.

1994 Flintknapping: Making and Understanding Stone Tools. Austin: University of Texas Press.

YI, S.

1989 A Study of the Paleolithic in Northeast Asia. Seoul: Seoul National University Press (in Korean).

1990 The Paleolithic in Northeast Asia. Seoul: Seoul National University Press (in Korean).

1996 Chronostratigraphy of Paleolithic occurrences in the Imjin Basin. Hanguk Kogo Hakbo (Journal of the Korean Achaeological Society) 34:135-159 (in Korean).

1999 On the temporal change of Korean Paleolithic industry. Paper presented at the Symposium to Commemorate the $80^{\text {th }}$ Birthday Celebrations of Professor Chosuke Serizawa, in World Views on the Early and Middle Paleolithic in Japan: 115-120, assembled by Tohoku Fukushi University, Japan. 
2000 Middle-Upper Paleolithic transition in Korea: A brief review. Hanguk Guseokgi Hakbo (Journal of the Korean Paleolithic Society) 4:17-24.

2001 For the advancement of the Korean Paleolithic research, in Paleolithic Culture in Korea: 327-339, assembled and published by Yonsei University Museum, Seoul (in Korean).

2002 Jangsanni: A Lower Pleistocene-early Middle Pleistocene Palaeolithic Locality in the Imjin River Basin: Preliminary Report. Hanguk Kogo Habo (Journal of the Korean Archaeological Society) 46:81-105 (in Korean).

Yi, S., AND G. Clark

1983 Observations on the Lower Paleolithic of Northeast Asia. Current Anthropology 24:181202.

YI, S., AND K. LEE

1993 Chuwolli and Kawolli (Juwol/Gawol-ri) Paleolithic Sites, Imjin River Basin, Korea. Seoul: Seoul National University (in Korean).

Yi, S., T. SOdA, AND F. Arai

1998 New discovery of Aira-Tn ash (AT) in Korea. Journal of the Korean Geographical Society $33(3): 447-454$.

Yi, S., Y. Yoo, ANd C. SeONG

2000 Pyeongchang-ri Paleolithic Site in Yongin, Korea. Seoul: Kyonggido Provincial Museum and Seoul National University (in Korean).

\section{ABSTRACT}

The present study challenges the widespread notion of an unchanging crude technology of quartzite and vein quartz assemblages in the Korean Paleolithic. Though mostly coarse and tough, the raw materials vary in texture, homogeneity, and thus quality in lithic manufacture, which in turn is the main reason why there is significant variability in the lithic technology. In contrast to the common impressionistic assumption, these materials produce not only large tools but also small flake tools. The examination of Paleolithic assemblages from the middle Korean Peninsula shows differences in raw material use in making artifacts of various form and size. Using the local raw materials, which allowed for hard and sharp edges when flaked, was a very effective strategy in lithic technology. KeYwords: lithic technology, Paleolithic, quartzite. 